\title{
Engaging in the internationalization of education and SDGs: Case study on the global hub of UNAI on sustainability
}

\author{
Rafis Abazov ${ }^{1^{*}}$ \\ ${ }^{1}$ MDP Global Classroom Program, Joint Program between Al Farabi KazNU and MDP Program at \\ Earth Institute at Columbia University, Earth Institute at Columbia University, Almaty, Kazakhstan
}

\begin{abstract}
The education sector has been identified as one of the key players in globalization processes and implementation of the UN Agenda 2030. The role of education, including higher education, involves not only raising awareness among young people and educators about the sustainable development goals (SDGs) and global environmental changes, but also in mobilizing them for partnerships towards fulfilment of these goals (as defined in SDG-17) and dealing with the challenges of globalization. The purpose of this article is to analyze the engagement of HEIs in internationalization of education, realization of the UN Agenda 2030 and supporting the implementation of SDGs, using as an example the work of the UNAI at the university level. First, the article provides a short literature review on empirical and theoretical aspects of the internationalization of HEIs, looking at how international institutions impact internationalization, organizational culture and the formulation of educational process and international cooperation activities at HEIs. Second, it analyzes organizational tools for internationalization by looking at the international experience and activities of university networks such as UNAI and the impact of those networks on the internationalization of universities. Third, it presents a case study of the work of an international university network, using the example of UNAI Hub at Al-Farabi Kazakh National University, and discusses how the UNAI programs have impacted the perception of internationalization and organizational culture at the university.
\end{abstract}

\section{Introduction}

An important but difficult task for higher education institutions (HEIs) in both developed and developing countries has been establishing tools and mechanisms for engaging young people in internationalization and global governance (GG) programs and education for sustainable development (ESD) [6], and implementing sustainable development goals (SDGs). Indeed, the preparation of young professionals to deal with major challenges of the $21^{\text {st }}$ century such as global governance, climate change, the introduction of a green approach in developing economies, and implementing sustainable social and economic development programs and innovations - is vital for the successful implementation of the UN Agenda 2030. Some studies suggest that HEIs make a significant contribution to awareness raising about SDGs among the public by implementing ESD and bringing international programs

*Corresponding author: r.abazov@yahoo.com 
and activities into the public domain [9]. However, there are many problems, challenges, and barriers undermining the effectiveness of introduction of ESDs and moving towards the implementation of the UN Agenda 2030.

On the one hand, many universities have pledged to promote GG programs and education for sustainable development through various means and channels, from internationalization of the educational process to such steps as incorporating new innovative courses into existing traditional educational programs, student-led research activities (such as capstone study projects), green campus initiatives, and a range of extracurricular events [4]. On the other hand, ESD is relatively new concept both for students and faculty members in construction of a new educational and learning paradigm $[23,4,25]$. Very often the promotion of programs on GG, ESD and SDGs has tended to rely on the enthusiasm of individual faculty members and senior administrative personnel, and the number of courses is often limited and unevenly spread between faculties

In this context it was envisioned that the United Nations Academic Impact (UNAI) program - an international network of universities, individual schools, and major stakeholders - would become an important initiative in promoting better knowledge about GG and SDGs and an important tool in developing better exchanges of best practices and lessons learned throughout the network of UNAI member universities across the world [10]. It was also expected that the UNAI would help to promote better understanding of the UN Agenda 2030 by changing perceptions and involvement of HEIs students, faculty, and management as well as organizational arrangements for ESD, including organizational culture $[9,26]$.

\section{Research purpose and review of questions}

The purpose of this article is to assess the internationalization of the educational process at universities around the world in the implementation of programs on GG, ESD and SDGs. This includes analyzing the promotion of ESD and engaging in realization of the UN Agenda 2030 and awareness about GG and SDGs using as an example the work an international university network at the university level: UNAI Hub in Kazakhstan.

The main instrument for measuring the internationalization process is the survey of perceptions of faculty members and university managers using a questionnaire-based survey study addressing three sets of issues:

The first question was designed to assess the perception of major directions, activities, and features of the development of internationalization of universities.

The second question was designed to overview the influence of international university networks on internationalization initiatives in the case of UNAI's work at the university level.

The third question was intended to study how the activities of UNAI affected organizational culture at higher education institutions, and the ways different subdivisions perceive and are involved in the internationalization process.

\section{Study objective and subject}

The main objective of this research is to evaluate the most significant factors and institutions impacting the internationalization of education and international cooperation at higher education institutions using an example of international university networks: UNAI Hub at KazNU. The researchers assume that international institutions/organizations might play an important role in the process of internationalization. Therefore, the subject of the study is the work of the Global Hub of UNAI on Sustainability at Al-Farabi KazNU, especially its impact on the established education system and procedures, on the interplay between different 
subdivisions of the university, as well as on organizational matters (such as the dynamics of relations along top-to-bottom and bottom-to-top lines).

\section{Importance of the study}

The importance of the study derives from the need to search for more effective ways to engage universities in the internationalization of higher education, the introduction and promotion of programs on GG and ESD, and awareness raising about SDGs. As more and more countries especially in the developing world move towards greening their economies and working on the implementation of SDGs, they need to educate and train significantly more young professionals to be able to deal in the most efficient and innovative ways with such issues as the challenges of SDGs, including global governance, climate change, growing pollution and environmental degradation, and human-caused disasters. Therefore, it is essential to assess the role of key global institutions such as international university networks - in promoting effective intra-university and inter-university collaboration in dealing with global challenges of GG, ESD and SDGs, promoting best practices in internationalization of education within universities as well as between members of the international university networks such as UNAI.

\section{Problem statement}

Many universities around the world have attempted the internationalization of education and introduction of international programs (such as ESD) in various ways, from stand-alone elective courses on SDGs, the UN, UNESCO [29], globalization and global governance at selected faculties to institution-wide foundation programs and courses [15]. Not all of these experiments in the internationalization of education have been successful, as universities have sometimes failed to effectively organize the promotion of new subjects or to effectively pair the interests of students and new subject content to attract sufficient attention or support from student communities and faculty members. In counterpoint, however, some universities have not only created their very own successful international programs (e.g., ESD), but have also established successful international joint programs through internationalization and effective collaboration with various partner institutions, alongside cooperation with private and public sector stakeholders through international university networks.

\section{Literature review}

This section provides an overview of literature covering the recent debates and research on the internationalization of higher education and the main institutional tools for attaining internationalization programs and strategies, with a focus on external institutional tools such as international university networks, organizations, and programs. The section also touches on how scholars view the impact of these institutional tools and internationalization programs on the university's organizational environment, especially organizational culture.

Studies on the internationalization of education and its impact on the formulation of educational process and management of HEIs suggest that the internationalization of education has become an important driving force in introduction of innovations in management of HEIs, international standards, reforming educational processes, changing educational programs, and changing organizational culture in HEIs over the past two decades $[14,12]$. Some scholars consider that universities around the world are embracing globalization and moving towards the standardization of educational processes through implementing international educational programs, adopting globally oriented management 
approaches, and participating in international ranking $[20,11]$. Others suggest that the impact is more modest, seeking to incorporate international standards even while retaining national traditions in higher education processes and management [5]. Yet others view that many universities, especially in the developing world, use the internationalization process and participation in international programs and associations as a tool for strengthening the existing national educational and managerial approaches $[23,13]$.

Various studies suggest that HEIs utilize different approaches, strategies, and practices that ultimately shape outcomes of actual internationalization, in order to move forward with the internationalization of education processes. One of the tools often employed by universities around the world, and especially in the developing world, is engagement with a range of international institutions such as international university networks, associations, ranking agencies, and others. As HEIs vary significantly in size, structure, managerial approach, and value systems, they have different strategies for engaging international institutions in achieving their specific goals and objectives. Some of them work with international institutions in order to use "the external drivers of change inherit in the higher educational environment and overarching global and societal trends" [16]. While universities have different rationales, motivations, and visions for engaging in the internationalization process, very often their ultimate goal is to promote changes in organizational culture in order to depart from existing historical educational traditions and practices, and to embrace new norms and approaches that better reflect the needs of more than the labor market and the challenges of the $21^{\text {st }}$ century [11]. These studies suggest that international university networks are important for achieving HEIs' educational goals and objectives.

Robert Middlehurst of Kingston University, UK, in discussing perspectives on global university networks, argues that "the development of international consortia and networks [is] a response to major historical-structural changes in higher education" [19]. Indeed, international university networks have become effective mechanisms in mobilizing academic communities and educational managers to acquire important technical and educational expertise, learn about relevant international best practices, and advocate for new educational models and managerial structures. Chapman and colleagues argue that establishing multiuniversity networks "can be a useful mechanism for promoting a social and educational agenda while at the same time strengthening the capacity of participating universities" [8]. The strength of international university networks lies in having brought a multitude of universities together around thematic issues, shared values, and social responsibility activism [19]. In fact, a number of international university networks have emerged in different parts of the world to advance the concept of the green campus, bringing HEIs together for research and academic exchanges on social innovation and responsibilities, ${ }^{\dagger}$ and for promoting a sustainable development agenda [24]. One example of such an initiative is the establishment of the United Nations Academic Impact (UNAI) program, initiated by the United Nations with support from a group of leading international experts on sustainable development. At the global level, the UNAI focused on building a horizontal international university network by establishing partnerships between HEIs and mobilizing student youth and academia in the support of UN principles and SDGs (for more information see the UNAI website: UNAI, n.d. $[27-28])$.

\section{Educational contexts}

Kazakhstan has been among the first countries in the Central Asian region to work systematically on reforming its higher education system and supporting the

\footnotetext{
† See for example, the work of the University Social Responsibility Network (USRN), which was established in 2015. Please follow the link: http://www.usrnetwork.org/about-usrn/background
} 
internationalization of educational processes. These reforms have been actively implemented through the reorganization of the educational process utilizing internal push-and-pull mechanisms, and various monetary and non-monetary stimuli [18]. One of the tools for stimulating and encouraging internationalization has been engagement with international university networks for the promotion of international standards and qualifications, and introduction of new education programs, including joint international programs. The local scholars argued [20] that Kazakhstan has actively promoted the internationalization of education utilizing instruments such as international academic exchanges, invitation of international faculty, joint research activities, and participation in a range of international academic associations and organizations. At the same time, the country has been widening the involvement of faculty and students in international programs in order to change the organizational culture in managing international programs and the ways in which educators and students are involved [17].

Like many universities around the developing world, Al-Farabi KazNU has been a relative latecomer in promoting education for sustainable development and incorporating sustainable development and other globalization-related topics into educational programs at the faculty level [7]. Since the early 2010s, Al-Farabi KazNU has attracted one of the largest bodies of international students and faculty and has signed MoUs with many foreign partners including leading universities and international organizations [10]. A major tool for improving implementation of the internationalization process at the university has been the promotion of joint programs, joint activities with various international university networks, and embodying some international programs into KazNU's organizational architecture by establishing joint labs, centers, and research institutions as well as organizing research activities and public events [4-5, 1-3].

Although the UN General Assembly officially launched the United Nations Academic Impact in 2011, it is the work of UNAI jointly with various international programs that has stimulated the development of interest in global governance and ESD (and later in SDGs) among senior management, faculty members, and students at KazNU. One of the most important innovations suggested by managers of the UNAI Hub at KazNU has been a carefully built system of consultations and trainings involving students and young faculty members from different faculties into the various UNAI programs. For example, UNAI Hub at KazNU contributed to discussions (at the national and international level) of innovative approaches to teaching ESD, selecting research topics for capstone and graduate projects, identifying topics for international seminars and international career events, and identifying top-notch international speakers [3]. These activities made significant input to changes in organizational culture and intra-university collaboration by setting goals and objectives, and establishing and ensuring values and purposes. The UNAI Hub at KazNU (which received the status of Global Hub of UNAI on Sustainability in 2014) initiated several publications about the activities of the executive committee, which focused both on changing organizational arrangements by creating faculty activities and on changing organizational culture by stimulating a bottom-up approach and encouraging students and young faculty members to come up with innovative educational initiatives [1-3].

\section{Methods of data collection}

The research team members for this project identified respondents for data collection in several steps. The team also conducted an assessment of online blogs, news, and other publications about internationalization, international cooperation activities, and the work of various organizations (including the UNAI Hub at KazNU) from the website of Al-Farabi KazNU. They also identified and selected faculties according to two criteria: a) faculties most actively contributing to the activities of international university networks such as UNAI, and 
b) faculties regularly working on UNAI activities for the promotion of ESD and programs on SDGs and the UN at the University.

Four steps were designed to complete the selection of respondents who were involved in GG, ESD, SDGs, UNAI, and other related activities and or initiated their own programs such as workshops, conferences, seminars, trainings, and/or study/research visits to foreign universities.

As the first step, the team conducted a series of additional phone interviews with the representatives of various faculties, in order to verify the list of faculty members for the survey study. The team identified a pool of potential participants in the selected seven faculties. Second, the research team developed a process for approaching potential interviewees from seven faculties according to two major criteria: a) educators, managers, and PhD students involved in GG, ESD, and/or UNAI related activities, and b) participants were selected to represent the cultural, gender, regional, and social diversity of the faculties of Al-Farabi KazNU. Third, the team members randomly selected participants for conducting interviews and questionnaire-based survey research out of this group of educators. Fourth, the team changed from the initially planned series of visits to the faculties for conducting face-to-face meetings with interviewees to online communication; thus, the procedure was redesigned to conduct the research using digital online tools and platforms, due to the lockdown restrictions in the 2020 and 2021 academic years.

\section{Data collection}

The actual data collection was designed to reflect new realities on the ground and was conducted in three steps. First, the research team contacted the representatives of selected faculties within Al-Farabi KazNU identified during the preliminary stage for preparation of the pilot questionnaire-based survey, explaining the goals, objectives, and research methodology of the study according to initially set criteria. Second, they emailed the questionnaire to coordinators at the faculties to contact randomly selected representative respondents and on some occasions the team emailed a questionnaire directly to the interviewees. Third, randomly selected respondents from each faculty received the questionnaire consisting of three research questions. The respondents had an opportunity to express themselves freely and anonymously to articulate their answers to the proposed questions of the research about the specific case study - the role of UNAI in the internationalization of education.

All questionnaires (total of 21) were received back, with the names replaced by codes in order to achieve anonymity, and were processed and tabulated. The figures (qualitative data) that represent the findings of the study are presented in Table 1. This table is designed to make it easy to crosscheck corresponding answers with the questions on the questionnaire.

Table 1. Responses to the questionnaire-based survey study (TOTAL 21)*.

\begin{tabular}{|l|c|c|c|}
\hline \multicolumn{1}{|c|}{ Respondents from faculty: } & Question 1 & Question 2 & Question 3 \\
\hline Faculty of Geography 1 & B & B & D \\
\hline Faculty of Geography 2 & B & A & A \\
\hline
\end{tabular}

\footnotetext{
‡ Initially, the research team envisioned to organize a series of focus groups and person-to-person semistructured interviews. However, due to COVID-19 restrictions and a series of lockdowns at universities, the team decided to opt for a questionnaire-based survey online study with a set of open-ended questions. The research team members completed all organizational work and laid down the groundwork for conducting the research.
} 


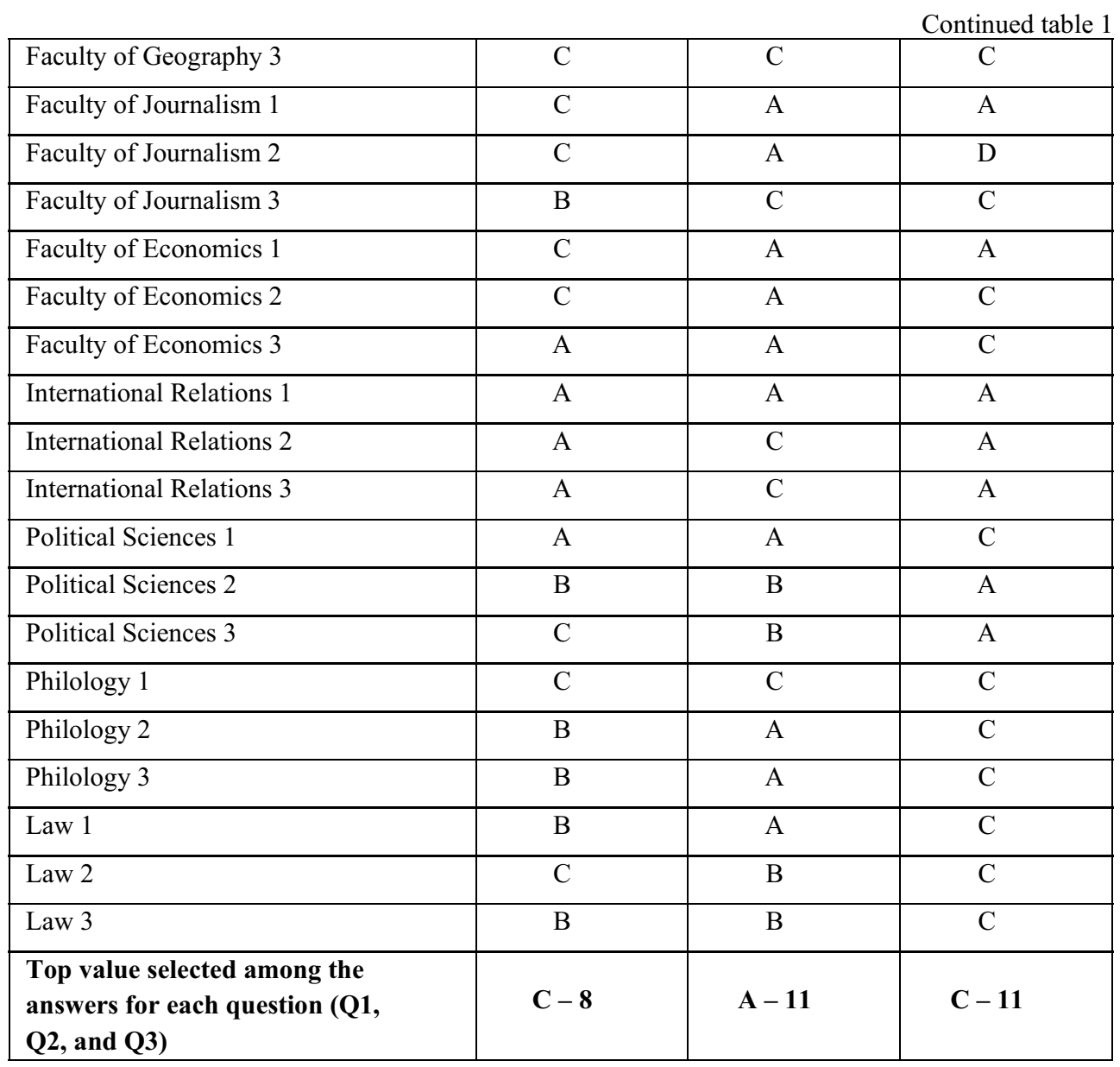

* For better visualization of presentation, the researcher coded the answers (please see the questionnaire in Appendix 2) as follows: A, B, and C

\section{Data analysis}

The research team with the help of coordinators from the selected faculties processed and verified all questionnaires for validity. After collecting all questionnaires, the results were coded and combined into a single database, and analyzed according to the research agenda and methodology. The data was systematized in a table (see Table 1), identifying key categories and approaches that emerged from the collected data. The researchers analyzed the results of the questionnaire-based survey and summarized both the qualitative and quantitative findings. ${ }^{\S}$

Overall findings of the study suggest that educators and managers at the university perceive positively the processes of internationalization of HEIs and involvement of the academic community in various activities including the work of international university networks. Indeed, most of the respondents have been involved in research or teaching

$\S$ This article provides a brief summary of the research project and presents only the main findings of the questionnaire-based survey due to limited space. 
activities and initiatives related to the internationalization and/or globalization of education through activities such as working on international relations, global governance, globalization, SDGs, UNAI, etc. The representatives of academia highlight the multi-level character of the impact of internationalization processes on the work of universities. At the same time, the respondents emphasize that universities might participate in the internationalization process with a different level of intensity and at different organizational levels (grassroots level; middle - faculties, chairs, and centers; and high level - top managers of universities).

The findings of the questionnaire-based research survey illustrate that respondents could be divided into three major categories according to their views and perceptions of UNAI and globalization.

The majority of respondents to the first question supported the internationalization of educational processes through international university networks - such as UNAI - as a way to involve students and faculty members in the internationalization of programs and activities on ESD, SDGs, etc. The qualitative answers to the first question included explanations and some detailed suggestions for how to move forward on teaching and/or research activities (such as globalization, international relations, academic capstone project, studies of SDGs, etc.). In addition, respondents suggested that engaging in the work of international university networks and various other activities - from accepting foreign students and scholars to join KazNU to sending students and faculty members from KazNU to foreign partner universities - would contribute to improving educational standards; updating curricula to meet the challenges of globalization, SDGs, and global climate change; and implementing international best practices for strengthening educational programs at host universities (e.g., Al-Farabi KazNU).

\section{Example 1 of an answer from the survey:}

"The work of the United Nations Academic Impact (UNAI) at KazNU should be focused through the development of the internationalization of education, which includes the points below: the study of international experience and best practices and integration into the international educational space and international networks. This is important, because internationalization is one of the main trends in higher education of our time and will contribute to the comprehensive implementation of [international] program."

Respondent X.

The majority of respondents to this second question (A11, see Table 1) agreed that the work of international university networks, such as UNAI, has contributed to the internationalization of education and educational processes at universities. This group also suggested that the work of UNAI and events organized by this university network (such as seminars, workshops, and conferences on theoretical and practical aspects of management of the educational process, and discussion of international best practices) has had practical implications at all levels - top university, faculty, and grassroots levels. One example mentioned by the respondents was the observation that events organized by UNAI contributed to improving management of international cooperation with foreign universities in general and of international projects and programs in particular.

\section{Example 2 of an answer from the survey:}

"Yes, it [the impact of UNAI] was at the [top-university] level by improving the management of projects for the internationalization of education in general. The United Nations Academic Impact (UNAI), its [work on disseminating] general information on additional engagement opportunities improves the process of project management at various 
faculties, as well as creates an atmosphere and a better basis for collaboration both within the university and promotes multilevel collaboration."

Respondent Y.

The majority of respondents to the third question (C11, please see Table 1) agreed with the notion that the activities of international university networks such as UNAI have contributed positively to changes in the organizational culture of universities in general (UNAI, 2011). The positive impacts include decentralization of decision-making on international collaboration and designing international projects. For examples, the respondents pointed out changes from a top-to-bottom to a bottom-up approach as increasing numbers of students and faculty members became involved directly in various internationalization-related activities, including activities involved in raising public awareness about the work of the UN and its agencies, the impact of globalization, the challenges of SDGs, work on ESD, and global climate change. Some respondents also mentioned that students and faculty members have become more proactively engaged in various public events and have even initiated their own events or suggested ideas and topics for future events.

\section{Example 3 of an answer from the survey:}

"I agree with this statement [UNAI bought some changes into the university], since the fact is noticeably visible that students have become more active and involved in the process of [university programs related to the increase of awareness about UN] programs. Many [students] began to take part in conferences, and participate in competitions at the international level. In terms of organizational aspects, the result is noticeable among the younger generation, as they quickly adapt to current conditions and bring a new vision and contribution to the development of projects."

Respondent Z.

\section{Conclusion and discussion}

This chapter summarizes the findings of the research and provides concluding thoughts about the role of international university networks - such as UNAI - in the changing nature of engagements between universities and in their organizational culture. This chapter also assesses the contribution of university networks in the internationalization of the educational context in the developing world, using the example of Kazakhstan.

In this context, the first important observation is the widespread acceptance of the need for internationalization, and the perception that internationalization of HEIs shapes global trends in development of the higher education sector across the world, which to various degrees impacts changes in educational processes at universities not only in the developed world, but also in developing countries. The second observation is that international institutions such as international university networks are becoming important tools in raising awareness about technological and social innovations in the education sector alongside global challenges and trends, and also are themselves becoming advocates and vehicles for the implementation of important changes at universities. The third observation is that the international university networks - such as UNAI - have an impact not only on education and research programs per se, but also on organizational culture within universities. The fourth observation is that the academic community is far from uncritically accepting the need for internationalization of education and engaging with the outside world through a given range of institutional tools. They also search for nuanced internationalization processes, adapted to the specific needs of universities and national educational environments. The fifth observation is that there is a need for further in-depth qualitative and quantitative studies 
evaluating the internationalization process in general and responses from universities to the challenges of globalization, ESD, and the SDGs in particular.

The case of Al Farabi Kaznu - which probably reflects the perceptions among educators not only in Kazakhstan and Central Asian republics, but also in many other developing countries - suggests that the internationalization of education impacts HEIs in many ways and international institutions play an increasing role in this process. On the one hand, the international institutions - such as UNAI - impact the contextual characteristics of the educational process helping to introduce and a wide range of new subjects related to IR and globalization in order to meet the interests of students and academic communities. The international institutions very often play a magnifying role in the process (though often in indirect way) in shaping educational process; however, they are often directly involved in intellectual discourses such as international workshops and conferences. On the other hand, the international institutions impact significantly less the institutional setting at HEIs, including organizational structures, management and organizational cultures, as management and faculty members at universities very often follow traditional administrative policies and approaches to the formulation of educational process deeply institutionalized in academic traditions at most of universities. The findings of the study suggest that the interaction between traditions and innovation is an ongoing process, with different groups among students and academia continue the dialogue about the dimensions of institutional changes. Yet, the internationalization process plays an increasingly visible role in institutional process contributing to the decentralization of decision-making (changes from a top-to-bottom to a bottom-up) not only in planning curricula, but also in shaping the intensity of international cooperation especially in intensity of multi university research and exchanges activities. A wide range of strategies and practices at various universities shape the process of internationalization of education and thus it is crucial to continue future qualitative and quantitative studies to investigate further the process of internationalization of education and the role of international institutions in this development.

Acknowledgements and research note: This article is a part of the larger study undertaken on the internationalization of higher education and education for sustainable development. The full-scale research on this topic was envisioned to start at the beginning of 2020. Initially it included a series of focus groups, semi-structured interviews, and questionnaire-based survey study.

However, due to the COVID-19-related lockdowns and restrictions, the initial plans were adjusted and the research was divided into a series of mini studies. The first study covered the introduction of ESD, using the example of the MDP program at al-Farabi KazNU. The second study covered the introduction of global citizenship education at the university level. The third study was envisioned to cover the impact of global institutions and initiatives, such as UNAI, on the internationalization of higher education and the introduction of ESD.

Thank you note: The author would like to express his gratitude to his colleagues for their support, encouragement, and comments on an early draft of this paper as follows: Mukhametkali Burkitbayev, Galiya Ibraeva, Tursunkul Bazarbayeva, Bibinaz Almanova, Maiya Suyunchaliyeva, Zhansaya Isayeva and many other colleagues.

\section{References}

1. Al-Farabi KazNU. Al-Farabi KazNU for Shaping Common Future. Almaty (Kazakhstan): Al-Farabi Kazakh National University Press, 2020, http://unaihub.kaznu.kz/?p=2072\&lang=en 
2. Al-Farabi KazNU (b). Al-Farabi KazNU Sustainability Report. Almaty (Kazakhstan): Al-Farabi Kazakh National University Press, 2020, http://unaihub.kaznu.kz/wpcontent/uploads/2020/10/al-Farabi-KazNU-Sustainability-Report-2020.pdf

3. Al-Farabi KazNU (c). Al-Farabi KazNU Global Hub of UNAI. Almaty (Kazakhstan): Al-Farabi Kazakh National University Press, 2019,http://unaihub.kaznu.kz/wpcontent/uploads/2020/10/al-Farabi-KazNU-Global-Hub-of-UNAI.pdf

4. R. Abazov. Herald of Journalism, 58, 4 (2020)

5. R. Abazov. Journal of Philosophy, Culture and Political Science, 75, 1 (2021

6. V. Andreotti. Postcolonial Perspectives on Global Citizenship Education (Routledge Research in Education Book 68). First Edition (New York, Routledge, 2012)

7. P. Chabal, K. Baizakova, A. Utegenova, R. Alipkyzy. International Relations and International Law Journal, 84, 4 (2018)

8. D.W. Chapman, A. Pekol, E. Wilson. International Review of Education, 60 (2014)

9. Angel Oi Yee Cheng. Global Mission - "Glocal" Internationalization: United Nations Academic Impact (UNAI) and Lehigh University. (2019). (Research in progress).

10. R. Damodaran. A Message from UN Academic Impact: “Why We Care” (July 20, 2020), https://www.peace-ed-campaign.org/a-message-from-un-academic-impact-whywe-care (2021)

11. M. Dobbins, C. Knill. Higher Education Governance and Policy Change in Western Europe: International Challenges to Historical Institutions. New York and London: Palgrave Macmillan (2014)

12. A. Erdogan. Current and future prospects for the Bologna Process in the Turkish higher education system. In: A. Curaj, L. Matei, R. Pricopie, J. Salmi, \& P. Scott (eds), The European Higher Education Area. Springer (2015)

13. B. Ghebru, M. Lloyd. From civic to citizenship education: toward a stronger citizenship orientation in the Ethiopian CEE curriculum. International Journal of Educational Development, 72, 102-143 (2020)

14. J. Gregersen-Hermans, K. M. Lauridsen. (eds). Internationalising Programmes in Higher Education: An Educational Development Perspective (Internationalization in Higher Education Series) 1st Edition (New York, Routledge, 2021)

15. H. Harper, J. Dunkerly. Educating the world: teachers and their work as defined by the United Nations Educational, Scientific and Cultural Organization (UNESCO). Current Issues in Comparative Education, 12(1), 56-65 (2009)

16. J. K. Hudzik. Comprehensive Internationalization: Institutional Pathways to Success (Internationalization in Higher Education Series) 1st Edition. New York: Routledge, 2014.

17. A. Kuzhabekova, J. T. Lee. European Education, 52(4), 297-311 (2020)

18. M. Merrill, S. Yakubova, Z. Turlanbekova. Internationalizing quality assessment in Central Asia. International Higher Education, n. 64, March 2011., https://ejournals.bc.edu/index.php/ihe/article/view/8561 (2021)

19. R. Middlehurst. Perspectives on global university networks. International Higher Education, 81, 4-5 (2015)

20. G. Mutanov, M. Burkitbayev, G. Ibrayeva, G. Abdraimova. Kazakhstan in the European Higher Education Area (EHEA). In: The European Higher Education Area. Almaty, 2013, https://www.researchgate.net/publication/268155550 _Kazakhstan_in_the_European_Higher_Education_Area_EHEA_Issue_032013>. (2021) 
21. A. Nechtelberger, W. Renner, M. Nechtelberger, S. Supekova-Chovanova, M. Hadjimarkou, et al. Frontiers in Psychology, 8, 2017, https://www.frontiersin.org/articles/10.3389/fpsyg.2017.01977/full (2021)

22. V. O. Pomyalova, et al. Effect of the University organizational culture perception on students' commitment: the role of organizational identification. IOP Conf. Ser.: Mater. Sci. Eng. 940 012099, 2020, https://iopscience.iop.org/article/10.1088/1757899X/940/1/012099 (2021)

23. A. Seidikenova, A, Abdeljalil, A. Bakitov. Global Citizenship Education: Critical and International Perspectives. Cham (Switzerland): Springer (2020)

24. D. T. L. Shek, R. M. Hollister. University Social Responsibility and Quality of Life. A Global Survey of Concepts and Experiences. Cham (Switzerland, Springer, 2017)

25. J. Sparks, A. Ashirbekov, A. Li, L. Parmenter, Z. Jumakulov, A. Sagintayeva. Becoming Bologna capable: strategic cooperation and capacity building in international offices in Kazakhstani HEIs. In: A. Curaj, L. Matei, R. Pricopie, J. Salmi, \& P. Scott (eds), The European Higher Education Area. Springer (2015)

26. N. Trushkina, R. Abazov, N. Rynkevych, G. Bakhautdinova. Virtual Economics, 3(1), 13-32 (2020)

27. UNAI. About UNAI. n.d. Available at: $<$ https://www.un.org/en/academicimpact/page/about-unai > (2021)

28. UNAI. The United Nations Academic Impact Is Informed by a Commitment to Support and Advance Ten Basic Principles (2011), http://unaihub.kaznu.kz/?page_id=15\&lang=en (2021)

29. UNESCO. Global Citizenship Education: Preparing Learners for the Challenges of the 21st Century. Paris: UNESCO, 2014,

https://www.gcedclearinghouse.org/resources/global-citizenship-education-preparinglearners-challenges-21st-century (2021) 


\section{Appendix 1. Questionnaire}

Interview questions

This questionnaire is designed to explore the impact of the United Nations Academic Impact (UNAI) on the internationalization of higher education. We kindly ask you to answer in more detail, at least three sentences. Data processing and presentation will be completely anonymous.

Thanks a lot, in advance.

First question

At what areas do you think the United Nations Academic Impact (UNAI) should focus on at your university?

A) Developing the internationalization of education (for example, through the development of academic exchanges, etc.) (explain why) ...

B) Developing the study of international experience and best practices (Explain why) ...

C) Integrating Kazakhstan's universities into the international educational space and international networks (explain why) ...

D) There is no need to internationalize higher education (explain why) ...

Second question

In your opinion, has the United Nations Academic Impact (UNAI) influenced the internationalization of education at your university?

A) Yes, at the level of greater involvement of students and teachers in projects for the internationalization of education (explain why) ...

B) Yes, it was at the level of greater involvement of faculties in projects for the internationalization of education (explain why) ...

C) Yes, it was at the level of improving the management of projects for the internationalization of education in general (explain why) ...

D) No, it didn't have any impact (explain why) ...

Third question

Do you think that the United Nations Academic Impact (UNAI) has influenced organizational culture change at your university?

A) Yes, it did, improving the management of international programs and the internationalization of education at the level of university management (explain why) ...

B) Yes, it did, improving the interaction between faculties on the management of international programs and the internationalization of education (explain why) ...

C) Yes, it did by improving the involvement of student youth and teachers in the management of international programs and the internationalization of education (explain why) ...

D) No, it did not (explain why) ... 